diluted ink. By this means preparations can be made of a variety of fungal material, including that obtained directly from infected plants, results being particularly valuable when such material is delicate and subject to distortion by fixing, as, for example, with asci of Eremascus.

Botany School,

Cambridge. May 15.

${ }^{1}$ Duguid, J. P., J. Path. and Bact., 63, 673 (1951).

\section{The Cuticle of Nematode Larvæ}

THE infective larval stage of many nematode parasites is ensheathed in the uncast cuticle of the second stage. The sheath is regarded as having some protective function in a larval stage which is more resistant to environmental fluctuations than the earlier stages. A method has been devised for separating the sheaths from larvæe, and it has been found that their protein complement is water-soluble. In this communication, the amino-acid composition of these proteins is discussed.

Mixtures of third-stage larvæe of Oesophagostomum, Ostertagia, Chabertia, Haemonchus and Trichostrongylus from sheep were examined. Pure samples of Haemonchus contortus larvæ were also used.

Exsheathment was obtained in vitro using solutions of sodium hypochlorite, as described by Lapage. As soon as exsheathment occurred the larvæ were centrifuged, the supermatant removed and the cuticles separated from the active larvæ by differential centrifugation in saturated sodium chloride. The cuticles were then washed five or six times in distilled water and placed in sealed tubes at $105^{\circ} \mathrm{C}$. for $12 \mathrm{hr}$. This caused the solution of the cuticles in distilled water, leaving a slight residue which microscopically was seen to be plant debris and which gave a negligible ninhydrin reaction after acid hydrolysis.

The cuticles in solution were hydrolysed in sealed tubes at $105^{\circ} \mathrm{C}$. in $6 \mathrm{~N}$ hydrochloric acid for $24 \mathrm{hr}$. The hydrolysate was examined by two-dimensional paper chromatography using 80 per cent ethanol and water-saturated phenol as solvents.

By comparison with a prepared map of known amino-acids, the presence of nine amino-acids was demonstrated in the hydrolysates of both mixed collections and pure samples of Haemonchus contortus. These amino-acids in approximate order of the amounts present were proline, hydroxyproline, aspartic acid, cysteic acid, glutamic acid, alanine, leucine, glycine and valine. This order was obtained on considering the size of the spot and the sensitivity of the different amino-acids to ninhydrin as estimated by Dent ${ }^{2}$. The first four were recognized by their position, colour and conformation. The presence of leucine and valine was verified using a marker procedure. Proline was detected by its colour in ninhydrin and isatin; hydroxyproline by its similar colour in ninhydrin and isatin and its specific red colour on the application of Ehrlich's reagent after isatin. Glycine was recognized by its colour, and though its position on the map could have been shared with arginine and serine, these two amino-acids were proved to be absent by other tests. Tests for cystine and tyrosine also gave negative results.

The presence and composition of water-soluble exoskeletal protein in the Invertebrata has been firmly established in the Insecta by several workers, most recently by Hackman'. The presence of some- what similar water-soluble protein in the nematoda has also been demonstrated in the cuticle of Ascaris by Chitwood ${ }^{4}$ and the amino-acid composition of an 'albumen' in the outer layer of fertilized Ascaris eggs has been demonstrated by Kreuzer ${ }^{5}$. It seems probable that water-soluble exoskeletal proteins may occur over a wide range of the invertebrate animals.

I am indebted to the Seience and Industry Endowment Fund of the Commonwealth Scientific and Industrial Research Organization for a personal grant. Assistance provided by the Agricultural Research Council is also acknowledged.

Department of Zoology,

AlAN F. BIRD

University of Adelaide, South Australia.

$$
\text { May } 14 .
$$

${ }^{1}$ Lapage, G., Parasitology, 27, 186 (1935).

2Dent, C. E. Biochem. J., 43, 169 (1948).

${ }^{3}$ Hackman, R. H., Biochem. J., 54, 362 (1953).

- Chitwood, B. G., Proc. Hel. Soc. Wash., 3, 39 (1936)

${ }^{5}$ Kreuzer, I., Z. vergl. Physiol., 35, 13 (1953).

\section{Newly Fallen Snow and Air Temperature}

The physical features of a layer of fallen snow at a given time are chiefly dependent on (1) meteorological conditions while the snow is falling, and (2) meteorological factors which occur later causing metamorphosis of the snow.

Some observations I have made in the Italian Western Alps have shown that the apparent density of newly fallen snow is variable and depends on air temperature during the fall. On account of the lack of systematic high-altitude observations in Italy showing low negative temperatures (centigrade), I have worked on the accurate data gathered at the Weissfluhjoch $(2,540-2,660 \mathrm{~m}$.), near Davos (Switzerland), already published. Excluding the cases of new snow less than $10 \mathrm{~cm}$. deep and snowfalls occurring with strong wind (causing Schneetreiben), as well as those with air temperature reaching or near $0^{\circ} \mathrm{C}$., it was found that the apparent density of the newly fallen snow depends upon the mean air temperature during the fall (see Fig. 1). The mean values of the air temperature are somewhat approximate, as deduced from the maximum and minimum temperatures, as well as from observations at $7 \mathrm{hr}$. $30 \mathrm{~min} ., 13 \mathrm{hr} .30 \mathrm{~min}$. and $21 \mathrm{hr} .30 \mathrm{~min}$., during the time of snowfall; however, they are referred to the

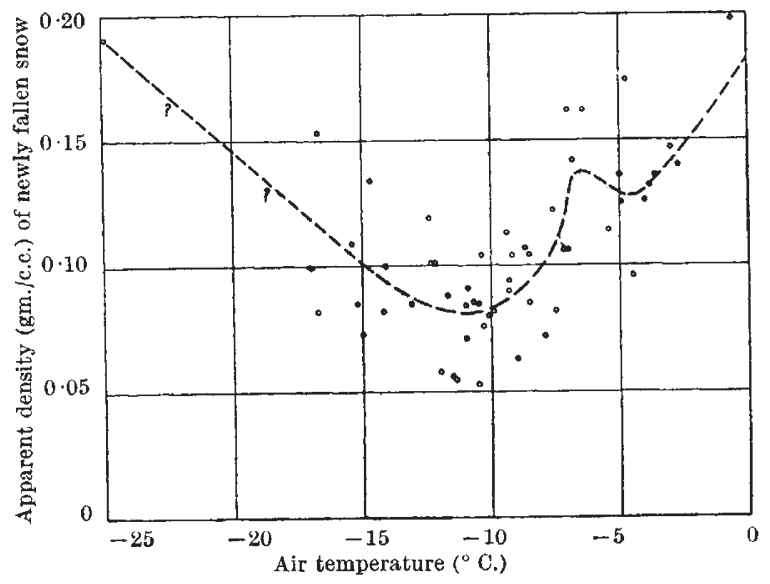

Fig. 1 